\title{
NORUS
}

ISSN: $2318-1966$

v. 4, n. 5

jan - jul 2016

Artigos

\section{A CIÊNCIA MODERNA E SUA CONSOLIDAÇÃO: É POSSÍVEL FALAR EM CRISE SOCIAL E EPISTEMOLÓGICA?}

Gabriel Bandeira Coelho

Mestre em Sociologia pela Universidade Federal de Pelotas (2015).

Professor do Instituto de Ciência Tecnologia IFSUL Campus/Pelotas.

\begin{abstract}
RESUMO
Este trabalho tem como objetivo apresentar as nodais características da Ciência Moderna, desde a sua emergência inclusive aquilo que tem sido cunhado como esgotamento e até mesmo "crise" da modernidade. Para tanto, destacamos aqueles que consideramos os proeminentes pensadores modernos, sobretudo René Descartes, cujo método cartesiano tem sido base epistemológica do conhecimento científico moderno. Ademais, mostramos aspectos sociais e teóricos que destacam o processo de consolidação da Ciência Moderna, principalmente no decorrer do século XIX, bem como elementos que nos ajudam a identificar possíveis sinais de falta de fôlego dos pressupostos modernos para explicar o mundo fenomênico contemporâneo.
\end{abstract}

Palavras-Chave: Interdisciplinariedade; Ciência; Disciplinariedade; Complexidade.

\section{THE MODERN SCIENCE AND ITS CONSOLIDATION: IS IT POSSIBLE TO TALK ABOUT SOCIAL AND EPISTEMOLOGICAL CRISIS?}

\begin{abstract}
This paper has as objective to present the notes characteristics of modern science, since its emergence including what has been coined as exhaustion and even "crisis" of modernity. Therefore, we highlight those we consider prominent modern thinkers, especially René Descartes, whose Cartesian method has been epistemological basis of modern scientific knowledge. Moreover, we show social and theoretical aspects that underline the Modern Science consolidation process, especially during the nineteenth century, well as elements that help us identify possible signs of breathlessness of modern assumptions to explain the contemporary phenomenal world.
\end{abstract}

Keywords: Interdisciplinarity; Science; Disciplinarity; Complexity.

\section{INTRODUÇÃO}

O presente artigo tem por objetivo central apresentar e identificar as principais características da Ciência Moderna, desde sua emergência e consolidação até a suposta crise de seus pressupostos balizadores, tais como: linearidade, fragmentação, análise, verdades universais e a 


\section{A Ciência Moderna e a sua consolidação: é possível falar em crise social e epistemológica?}

natureza como uma máquina perfeita regida por leis gerais e absolutas. Para tanto, abordarmos, em um primeiro momento, "A grande ruptura". Subitem este no qual elencamos o nascimento da modernidade, especialmente o marcante processo de ruptura entre a fé e a razão a partir da "Revolução Cientifica" edificada pelos eminentes pensadores modernos, como Nicolau Copérnico, Galileu Galilei, René Descartes, Francis Bacon, Joahannes Kleper, Isaac Newton, entre outros. Optamos, aqui, por dar maior ênfase ao pensamento cartesiano, posto que concordarmos que este último representa a própria ciência moderna, uma vez que o método analítico impulsionou, de fato, o progresso científico.

Além disto, em um segundo momento, salientamos no subitem denominado "A consolidação da ciência da modernidade" uma série de acontecimentos científicos, políticos e sociais que marcaram e contribuíram para a consolidação da Modernidade nos séculos XVII, XVIII e XIX, quais sejam: a análise cartesiana e o método dedutivo; o método indutivo de Bacon; a síntese do método dedutivo-indutivo preconizada por Newton; o surgimento da Sociologia com Auguste Comte e o ápice da escola positivista; a Revolução Francesa e a Revolução Industrial; as importantes descobertas da física, como a I Lei da Termodinâmica e a Teoria da Relatividade de Einstein. Com isto, o breve resumo que apresentamos dos principais pontos que marcaram este momento criativo do pensamento humano, revela-nos o quão importante foram os séculos XVII, XVIII e XIX para o progresso e o desenvolvimento do conhecimento científico.

Por fim, no subitem “A modernidade e o século XX: início de uma crise?” buscamos enfatizar os aspectos que podem, de certo modo, assinalar os sinais de instabilidade e de esgotamento das características - fragmentação, linearidade, análise, entre outros - do paradigma moderno. Neste sentido, na segunda metade do século XX, com a crise do positivismo lógico, alicerçado no método dedutivo-indutivo, ressaltada, sobretudo por Popper e, também com o surgimento da filosofia da linguagem hermenêutica e com a emergência das abordagens epistemológicas de orientação histórica, podemos observar a "tensão paradigmática", especialmente no que diz respeito a sua fundamentação epistemológica, teórica e metodológica, que tem caracterizado a racionalidade moderna a partir deste período. 
NORUS - v4, n.5, jan - jul 2016.

\section{A Ciência Moderna e a crise de seus pressupostos}

\subsection{A grande ruptura}

O processo de desenvolvimento do conhecimento humano é, indubitavelmente, marcado por crises e rupturas. Tais características destacam-se quando sublinhamos a mudança de episteme, nos termos de Foucault (2000), - para mostrar a descontinuidade histórica de diferentes saberes que passam a estruturar todo o conhecimento de uma determinada época - que ocorreu com a "Revolução Cientifica", realizada pelos pensadores modernos. Nicolau Copérnico, Galileu Galilei, René Descartes, Francis Bacon, Joahannes Kleper, Isaac Newton, entre outros fundaram, a partir do século XVI, o pensamento moderno e, consequentemente, a ruptura entre a fé e a razão. Segundo Alexandre Koyré (2010), em sua obra "Do mundo fechado ao universo infinito"- publicada originalmente em 1957 -, nos séculos XVI e XVII, o espírito humano passou por uma intensa revolução que, por sua vez, modificou os padrões do nosso pensamento. Essa ruptura na evolução do pensamento humano, isto é, na maneira de perceber o homem, Deus e a natureza e suas relações, fez emergir o que conhecemos atualmente como ciência e filosofia modernas ${ }^{1}$.

A evolução do pensamento científico não pode ser analisada independentemente da evolução das ideias "transcientificas, filosóficas, metafísicas e religiosas" (KOYRÉ, 1982, p. 11). Neste sentido, a forma de pensar o mundo dominante na Idade Média baseava-se no aristotelismo (escolástica). O aristotelismo caracterizava-se pela união entre a teologia cristã e pelas derivações do pensamento aristotélico, principalmente a física aristotélica ${ }^{2}$, e outros gregos que representaram a antiguidade. Tal concepção de mundo fora desenvolvida, no século XI, por Tomas de Aquino ${ }^{3}$ e resultou na formulação da ideia medieval, de um cosmo finito e ordenado hierarquicamente. Percebemos, a partir disso, que os pressupostos clericais - baseados na fé, num Deus onipresente e soberano e numa visão orgânica e espiritual, para quem a Terra era o centro do Universo - foram centrais para a explicação dos fenômenos do mundo durante séculos. No entanto, principalmente nos séculos XVI e XVII, essas crenças passaram a ser fortemente criticadas por inúmeros esforços

\footnotetext{
${ }^{1}$ Conforme Franklin Baumer (1977), o termo moderno precisa ser definido. Diz o autor: "pode significar [algo] recente ou aparente, o que implica que haja sempre 'modernos' em todas as gerações. Por outro lado, o termo pode referir-se a um conjunto de ideias e atitudes especificas” (p. 44). Neste sentido, assim como Baumer usa-o para remeter-se à "nova visão de mundo que (...) tornou-se uma força dominante na civilização europeia" (Baumer, 1977, p. 44-45), nós também utilizamos o termo moderno/ciência moderna para falar do novo pensamento que emergiu com a crise da tradição intelectual medieval.

${ }^{2}$ Para um maior aprofundamento da visão da filosofia da ciência de Aristóteles, ver Losee (1979, p. 15-26).

${ }^{3}$ Tomás de Aquino diferencia a filosofia da teologia, de acordo com o seu objeto de estudo. Assim, a Filosofia deve apontar para a compreensão da natureza, usando a razão para isso. Por outro lado, a Teologia deve dar conta daquilo que é sobrenatural, utilizando, dessa forma, a fé como instrumento (ANDERY et al.,1998).
} 


\section{A Ciência Moderna e a sua consolidação: é possível falar em crise social e epistemológica?}

teóricos, epistemológicos e metodológicos dos pensadores modernos que não mais admitiam as respostas do pensamento eclesiástico sobre o universo. Em outros termos, a episteme medieval esgotou-se frente à necessidade de novas explicações no que dizia respeito ao mundo fenomênico (KOYRÉ, 1982; SHORTO, 2013).

A revolução cientifica - muito além de um evento de transição entre paradigmas, nos termos de Thomas Kuhn (1996), é empregada por nós do mesmo modo que Alexandre Koyré (1982) a empregou para apontar o processo de surgimento da ciência moderna e a "morte da Idade Média" ou a crise intelectual, conforme Franklin Baumer (1997) também a nomeou, iniciou-se com Nicolau Copérnico, no século XVII, quando o mesmo contestou o modelo geocêntrico da Bíblia e de Ptolomeu (CAPRA, 1982). Foi neste momento que a Terra passou a condição de não mais pertencer ao centro do universo. Assim, o sol passou a ocupar essa posição central, caracterizando, deste modo, o modelo heliocêntrico do universo. Neste sentindo, Koyré (2010) aponta para a grande contribuição da teoria copernicana para o nascimento e posterior desenvolvimento da ciência moderna, afirmando que astronomia copernicana, ao remover a Terra do centro do universo, destruiu os alicerces da ordem tradicional do cosmos, bem como a sua estrutura hierarquizada. Outro importante pensador moderno fora Galileu Galilei com sua relevante teoria sobre as leis da queda dos corpos, no campo da astronomia, e sua divergência com as formulações aristotélicas, “consideradas por ele como não cientificas: 'movimentos naturais' em direção a 'lugares naturais"” (LOSEE, 1979, p. 64). Conforme Tamayo (2003), Galileu marcou seu espaço na gênese do conhecimento cientifico, devido ao uso de experimentos para a matematização do mundo e da ciência. Roland (1996), em uma mesma linha de reflexão, argumenta que, embora Galileu não tenha exposto explicitamente ${ }^{4}$, tais formulações resultaram no aparecimento da lei da inércia que, por seu turno, postula a ideia de que "um corpo que não está submetido a nenhuma força desloca-se em linha reta numa velocidade constante" (p. 52).

Considerando ainda os grandes nomes da gênese da ciência moderna, temos a formulação das três leis empíricas, por Johannes Kleper, acerca do movimento dos planetas, a saber: "a órbita de um planeta é uma elipse com o sol num dos focos; o raio vetor do sol ao planeta varre áreas iguais em tempos iguais e a razão dos períodos de dois planetas quaisquer é proporcional à razão dos cubos das suas distâncias médias do sol” (LOSEE, 1979, p. 59). Isto corroborou a visão heliocêntrica do universo de Copérnico. Relevante pensador fora, também, o inglês Francis Bacon, para quem a experimentação cientifica, baseada na observação de fenômenos particulares (método indutivo), era o caminho para chegar à verdade/conhecimento (conclusões gerais). Tal perspectiva

\footnotetext{
${ }^{4}$ Koyré (2011) afirma que a mecânica do principio da inércia está implicitamente baseada em Galileu.
} 
NORUS - v4, n.5, jan - jul 2016.

metodológica rendeu-lhe o título de "pai" do empirismo. Em resumo, e em relação a todos esses postulados que marcaram a intensa mudança espiritual do pensamento humano, Koyré (2010, p. 06) argumenta que:

\begin{abstract}
Essa revolução cientifica e filosófica causou a destruição do Cosmos (...), da concepção de mundo como um todo finito, fechado e ordenado hierarquicamente (um todo no qual a hierarquia de valor determinava a hierarquia e a estrutura do ser, erguendo-se da terra escura, pesada e imperfeita para a perfeição cada vez mais exaltada das estrelas e das esferas celestes), e a sua substituição por um universo indefinido e até mesmo infinito que é mantido coeso pela identidade de seus componentes e leis fundamentais, e no qual todos esses componentes são colocados no mesmo nível do ser.
\end{abstract}

Com efeito, foi a partir, sobretudo dos esforços filosóficos e metodológicos de René Descartes - arauto da filosofia e da cultura moderna ${ }^{5}$ - com a sua mais relevante obra: "O discurso sobre o método", que as ideias pré-modernas começaram a mostrar, de fato, sinais de esgotamento. O livro de Descartes - e neste caso concordamos com Shorto (2013, p. 35) quando afirma ser "a linha divisória da história do pensamento [entre medieval e moderno]"- e as descobertas da "nova filosofia" marcaram a gênese de uma nova forma de pensamento que irá, por sua vez, influenciar intensamente o mundo cientifico durante os séculos XVII ao XIX, estendendo-se até os dias de hoje. Tais descobertas dizem respeito à visão do mundo como uma máquina - a ideia cartesiana do mundo mecânico, como um relógio - regida por leis universais e invariáveis, ou seja, um universo infinito, homogêneo, dinâmico e atual (KOYRÉ, 1982). Em oposição ao pensamento tradicional medievo, o método analítico cartesiano consistia em dividir o todo em quantas partes fosse necessário para melhor conhecê-lo e tomava o corpo como uma máquina, cuja compreensão de cada parte que o constituía - separando a mente do corpo - bastaria para que ele funcionasse de forma ordenada. Nas palavras do próprio Descartes: “posso estar certo de que o corpo e a alma (...) são realmente distintos, posto que concebê-los clara e distintamente como separados, e de que a onipotência de Deus pode, por conseguinte, separá-los” (DESCARTES, 1983, p. 09).

Descartes (1983) postulava que o "verdadeiro" método científico era constituído por quatro grandes preceitos, quais sejam: o primeiro era, segundo ele, o de nunca acolher qualquer fenômeno como verdadeiro de forma apressada e precipitada; o segundo seria o de dividir cada uma das dificuldades encontradas em quantas parcelas fossem necessárias e possíveis e, deste modo, buscar solucioná-las; o terceiro diz respeito à conduta do pensamento, ou seja, deve a reflexão científica iniciar pelos objetos mais simples e mais fáceis de serem conhecidos, até chegar ao conhecimento mais composto e robusto; por último, o quarto preceito caracteriza-se por "fazer em toda parte [do

\footnotetext{
${ }^{5}$ Estamos de acordo com Alexandre Koyré no que tange ao ponto de referência dos estudos sobre a história da ciência clássica. Motta (2010, p. XIII), na apresentação da obra "Do mundo fechado ao universo infinito", de Koyré, aponta que: "é a ontologia axiomática fundada por Descartes que é a base do novo sistema de pensamento". Por esse motivo é que sublinhamos enfaticamente, na contextualização da gênese da modernidade, o método cartesiano.
} 


\title{
A Ciência Moderna e a sua consolidação: é possível falar em crise social e epistemológica?
}

fenômeno] enumerações tão completas e revisões tão gerais (...) sem nada omitir" (DESCARTES, 1983, p. 37-38).

Por conseguinte, é importante ressaltarmos que uma das principais características dessa ruptura é o surgimento de um individuo que duvida e que produz conhecimento livremente, ou seja, de um sujeito autônomo que reflete sobre si e o mundo. Um sujeito que pensa e, sem a manipulação divina e transcendental, reconhece que "as leis gerais da natureza eram supostamente consequências dedutivas de verdades necessárias" (LOSEE, 1979, p. 90). Dessa forma, em uma mesma linha de definição sobre o cartesianismo, Granger (1983, p. 23) afirma que "o cogito cartesiano está, assim, na origem de uma filosofia da consciência, [explicando], deste modo, o mundo, partindo da consciência como um dado evidente [levando o homem para o caminho da verdade]". Em relação à autonomia do sujeito cartesiano, explorando uma dimensão sociológica, Norbert Elias (1994) também faz uma importante consideração:

\begin{abstract}
Uma das precondições do pensamento de Descartes foi um certo afrouxamento, uma perda de poder por parte das instituições sociais que tinham sido guardiãs dessa tradição intelectual [tradição medieval]. Seu pensamento reflete a crescente conscientização de que as pessoas eram capazes de decifrar os fenômenos naturais e dar-lhes uma utilização prática simplesmente com base em sua própria observação e pensamento, sem invocar autoridades eclesiásticas (...). Em virtude da obra anterior dos pensadores da Antiguidade clássica, essa descoberta soou, a seus contemporâneos, como um redescobrimento. Foi o redescobrimento de si mesmos como seres capacitados a chegar por seu próprio pensamento e observação à certeza sobre os acontecimentos (...). E isso deslocou a atividade mental (...) e os poderes de percepção para o primeiro plano da autoimagem do homem (ELIAS, 1994, p. 84).
\end{abstract}

Tais concepções não foram bem vistas pelo clero, tampouco pelos intelectuais que resistiam em afastarem-se do dogma aristotélico. Eles argumentavam que o método cartesiano "levaria ao ateísmo, a uma quebra de autoridade, a um mundo repleto de dúvida e confusão, sem qualquer árbitro, quaisquer regras" (SHORTO, 2013, p. 44). Ademais, a oposição católica enfatizava "que o reconhecimento da matéria e do mundo material, feito por Descartes, questionava a doutrina da eucaristia e da presença real de Jesus Cristo na hóstia" ${ }^{6}$ (SHORTO, 2013, p. 83). Todavia, durante o decorrer do tempo, o cartesianismo começou a preencher espaços nos lugares em que fora conhecido. Professores, estudantes, intelectuais e demais membros da sociedade dos séculos XVII e XXIII passaram a ver o método da razão como fundamental para compreender o mundo e as leis que o regiam.

Diferentemente de Francis Bancon, que se utilizava do método indutivo para conhecer as leis gerais da natureza, e de outros empiristas, Descartes "estava comprometido com o ideal

\footnotetext{
${ }^{6}$ Para um maior aprofundamento desse debate, ver Shorto (2013, p. 70-76). Nem todos os católicos eram contra o cartesianismo, de acordo com Shorto (2013), grande parte dos primeiros adeptos ao cartesianismo eram padres católicos.
} 
NORUS - v4, n.5, jan - jul 2016.

arquimediano de uma hierarquia dedutiva [método dedutivo] de proposições”,7 (LOSSE, 1979, p. 83). Descartes (1983) evidenciou que só era possível produzir conhecimento a partir do uso da razão. Por isso a gênese do cogito cartesiano - Cogito ergo sum ou Je pense, donc jê suis (Penso, logo existo) -, destacando, assim, o pensamento como o locus onde funda-se a verdade universal e a certeza inabalável. Não obstante, o método cartesiano parte da perspectiva de que é preciso duvidar de tudo, pois não devemos confiar nos nossos sentidos. Quando não é mais possível duvidar, depois de tantos questionamentos (último grau da dúvida; a dúvida hiperbólica) o homem estaria diante da verdade segura sobre um determinado fenômeno. E a principal verdade é a existência de si mesmo como um ser pensante; nos termos de Capra (1982, p. 53), “a certeza cartesiana é a matemática em sua natureza essencial. Descartes acreditava que a chave para a compreensão do universo era a sua estrutura matemática; para ele ciência era sinônimo de matemática”. Dito de outra forma, Koyré destaca que:

O mundo de Descartes não é de modo algum o mundo colorido, multiforme e qualitativamente determinado dos aristotélicos (...). O mundo de Descartes é um mundo matemático rigidamente uniforme, um mundo de geometria reificada, de que nossas ideias claras e precisas nos dão um conhecimento certo e evidente. Não há nada neste mundo senão matéria e movimento (...) não há nada senão extensão e movimento (2010 p. 90-91).

Em verdade, o objetivo de Descartes, assim como o dos demais pensadores que inauguraram a modernidade, era o de controlar a natureza através de métodos científicos e, com isso, garantir o progresso humano. Descartes, dessa forma, questionava o não-progresso da humanidade durante a dominação do pensamento tradicional medieval.

Que tipo de método, então promoveria o progresso? Descartes era claro em relação a sua meta final. Diferentemente dos filósofos das eras anteriores, que se devotavam a questões do tipo 'Porque algo existe em vez de nada existir?', ele entregava-se por inteiro aos seus questionamentos: estava em busca do tipo de filosofia que agarraria o mundo pela garganta e tornaria os homens 'senhores e mestres da natureza (SHORTO, 2013, p. 36).

Frente a isso, percebemos que Descartes teve grande proeminência para os estudos científicos que se seguiram após o desenvolvimento do seu método analítico - vide o destaque da geometria analítica que, até os dias atuais, juntamente com o cálculo diferencial de Newton, faz-se presente nos bancos escolares. Essa nova forma de pensamento (cartesianismo) representou, por seu turno, um amplo protesto em relação às estruturas tradicionais que, alicerçadas na fé, dominaram os saberes humanos durante o período medievo. A analítica cartesiana, por sua vez, influenciou também, posteriormente, o Iluminismo francês. Além disso, contribuiu para o acelerado processo de

\footnotetext{
7“"As correntes objetivistas naturalistas e empiristas privilegiam a participação do objeto, dos fatos e da observação, enquanto as correntes racionalistas, idealistas e subjetivistas privilegiam o sujeito, a teoria e os conceitos" (SANTOS, 1989, p. 72)
} 


\section{A Ciência Moderna e a sua consolidação: é possível falar em crise social e epistemológica?}

desenvolvimento das ciências da natureza ao longo dos séculos posteriores à morte de Descartes, como a teoria newtoniana, por exemplo.

Conforme já descrevemos, a modernidade, em especial a ciência moderna, representou uma ampla ruptura com as estruturas tradicionais que sustentavam o pensamento humano e suas manifestações sociais. Nesse sentido, a revolução do método cartesiano, de modo geral, produziu um processo de descontinuidade no que tange a episteme medieval, dando ínicio ao processo de consolidação do conhecimento científico e levando ao desenvolvimento da sociedade e da própria ciência. Podemos dizer, então, concordando com Koyré (1982), que a descontinuidade encontra-se, especialmente, na reformulação de noções fundamentais, tais como movimento, espaço, saber e ser. A partir disto, conforme aponta Baumer (1977), a questão da natureza passou a ser central na concepção moderna de mundo. Segundo o autor, a problemática da natureza humana levou o homem a tomar consciência de seu próprio poder e, assim, compreender, controlar e organizar a sociedade num plano racional. Em outras palavras, a relação central para os modernos passou a ser, então, a relação entre o homem e a natureza e não mais entre Deus e o homem como no pensamento tradicional medievo.

\subsection{A consolidação da ciência na modernidade}

O pensamento cartesiano do universo como uma máquina perfeita, que funcionava a partir de leis mecânicas e que tudo no mundo baseava-se na explicação sobre organização e sobre o movimento de suas partes, fora utilizada como alicerce para a compreensão dos fenômenos naturais até as grandes mudanças da física no século XX (CAPRA, 1982). Assim, grandes pensadores marcaram seu espaço no cenário de consolidação da ciência. Neste sentido, no decorrer da história da modernidade, no século XVII, Isaac Newton foi o pensador moderno responsável por colocar em prática o arcabouço teórico e metodológico cartesiano, desenvolvendo, dessa forma, a base para que a revolução cientifica, iniciada por Descartes, fosse, de fato, deflagrada.

\footnotetext{
Descartes foi o fundador da 'nova filosofia', cujo trabalho foi levado adiante por Newton e por cientistas posteriores [...] Os princípios da 'nova filosofia', da teoria do conhecimento e da teoria da natureza humana que acompanham; os conceitos de uma ideia, das leis matemáticas da natureza (...) são tão fundamentais para a consciência moderna que fica difícil não considerá-las como parte da propriedade natural da mente humana (RÉE apud SHORTO, 2013, p. 89).
}

Em síntese, Newton conjugou as teorias de Copérnico, Galileu, Bacon e Descartes e concluiu "que fenômenos aparentemente desconexos na superfície são interligados e que há uma 
NORUS - v4, n.5, jan - jul 2016.

origem dinâmica comum aos movimentos dos planetas, da lua, dos cometas e das marés. A intervenção gravitacional é universal" (SCHWARTZ, 1992, p. 48).

Deste modo, é importante ressaltarmos que se Descartes fora o "pai do racionalismo moderno" ${ }^{\prime 8}$ - tendo a mente como ponto de partida para a obtenção da verdade -, Francis Bacon, John Lock, David Hume e George Berkeley são os mais relevantes empiristas, que, contrariamente ao cartesianismo, tinham no mundo empírico a base para o conhecimento sobre a natureza (SHORTO, 2013). Tal separação (racionalismo X empirismo) dominara os pressupostos modernos até a grande síntese newtoniana que uniu os dois métodos em suas investigações. Com efeito, Tamayo (2003, p. 62) aponta que:

As ideias de Newton sobre o método cientifico devem sua expressão a Descartes e a seus seguidores em vista de que o sábio inglês opunha-se ao método cartesiano, cujo objetivo era derivar as leis físicas básicas a partir de princípios metafísicos. Newton insistiu que as generalizações da ciência deveriam basear-se no cuidadoso exame da realidade. Em relação ao método cientifico, Newton era um aristotélico assumido e referiu-se a seus procedimentos indutivos-dedutivos como o 'método de análises e sínteses".

A afirmação de Tamayo em relação ao método newtoniano mostra-nos como Descartes tornou-se o ponto nodal para o desenvolvimento e consolidação da ciência moderna. Além de Newton, que afirmava "a unidade fundamental da matéria e da luz e concebia os componentes materiais do universo (...) como submetidas constantemente à ação de todo um sistema de várias forças não materiais de atração e repulsão" (KOYRÉ, 2010, p.184), e de outros pensadores influenciados pelo cartesianismo, Gottfried Leibniz poderia, em relação ao seu método, ser igualado a Descartes. Leibniz tinha por objetivo deduzir as leis e os princípios da natureza com base em princípios metafísicos evidentes, que poderiam, por sua vez, serem conhecidos a priori (TAMAYO, 2013). Em outros termos, os princípios de Leibniz postulavam que não fazia-se necessário ir ao mundo ou manter contato com a realidade empírica para conhecer a verdade, caracterizando sua aproximação ao método dedutivo.

Conforme o passar do tempo, após a gênese da modernidade, o mundo sofreu constantes transformações. Tal dinamicidade está inextricavelmente relacionada, sobretudo, ao desenvolvimento da ciência. Nestes termos, o século XVIII fora o período marcante para evidenciar as referidas mudanças, dentre elas: a descoberta do nitrogênio e da eletricidade; a primeira extração de apêndice; a invenção do imposto de renda; a descoberta das ilhas havaianas; a invenção da caneta-tinteiro; do extintor de incêndio; do piano; do diasapão e da descarga de vaso sanitário: além

\footnotetext{
8 “A carreira de Descartes, o foco de toda a sua vida na medicina ou na dissecação e na observação, torna menos nítido o rótulo do racionalismo (...)Ele foi fundamental tanto para a tradição racionalista quanto para a empírica, assim como para as ideias políticas do Iluminismo" (SHORTO, 2013, p. 89).

${ }^{9}$ Todas as traduções presentes neste trabalho são traduções livres realizadas pelo autor.
} 


\section{A Ciência Moderna e a sua consolidação: é possível falar em crise social e epistemológica?}

disso, ficaram mais sofisticados os relógios, os microscópios, as bússolas, as lâmpadas e as carruagens. Em Birmingham fora descoberto o oxigênio e o motor a vapor (...) além da construção das primeiras fábricas do mundo (SHORTO, 2013. p. 86-87).

Não obstante, uma importante divisão formava-se neste cenário de intensas descobertas e consolidação da ciência que envolvera duas grandes nações europeias. De um lado, a França iluminista, com sua abordagem sobre o conhecimento de forma alinhada, racional e também abstrata, caudatária da visão holística da realidade cartesiana. Isto fica nítido quando percebemos que os ideais que balizaram a Revolução Francesa no século XVIII, a saber, liberdade, igualdade e fraternidade, sem dúvida, estão calcados na perspectiva moderna sobre o progresso humano. Por outro lado, a Inglaterra, que via o pensamento de Descartes como uma caixa de ferramentas para a realização de experimentos, ou seja, para por em prática a matematização do mundo (SHORTO, 2013). Assim, "se os franceses criaram a nova filosofia, os ingleses inventaram a ciência aplicada, criando molas para relógio, ligas metálicas e cerâmicas vitrificadas" (SHORTO, 2013, p. 88). Em outras palavras, os séculos XVIII e XIX foram marcados por duas grandes revoluções. Uma de caráter econômico: a Revolução Industrial Inglesa e a outra, com características políticas: a Revolução Francesa (ANDERY et al., 1988).

Tais mudanças políticas, sociais e econômicas não passaram despercebidas aos olhos dos pensadores da época. Dessa forma, as correntes filosóficas que surgiram no século XIX são essenciais para entendermos como se deu o processo de desenvolvimento da ciência moderna. Estamos falando, sobretudo, do empirismo britânico, representado por John Herschel, Stuart Mill e William Whewell, e do positivismo francês, tendo como representantes, Auguste Comte, Ernst Mach, Charles Peirce e Sanders Poincaré (TAMAYO, 2003). Além disso, destacaram-se o pensador francês Emile Durkheim, e os pensadores alemães Karl Marx, Max Weber e Georg Simmel. O cenário social e cientifico de amplas transformações e inovações foi preocupação central para as formulações teóricas desses cientistas sociais. Racionalidade, classes sociais, fatos sociais, dentre outros conceitos exprimem o caráter das produções epistemológicas que emergiram no século XIX, dando ênfase ao contexto de intensas mudanças sociais que se apresentava.

Com efeito, é importante destacar o nascimento da Sociologia ou da Física Social, enquanto ciência, a partir do Curso de Filosofia Positiva de Auguste Comte, em 1830. Ao expor toda a evolução do conhecimento do espírito humano através da Lei dos Três Estados, Comte afirmava que tal evolução iniciou-se no estágio teológico, passando pelo estágio metafísico e chegando ao ápice com o estágio positivo do pensamento, onde está fundada a ciência e a inteligência humana (COMTE, 1983). Com base nisto, após todo o desenvolvimento do espírito humano 
NORUS - v4, n.5, jan - jul 2016.

(conhecimento), até chegar ao estado positivo - quando fundou-se a física celeste, a física terrestre (química e mecânica), a física orgânica (vegetal e animal) -, restava então nas palavras de Comte, "fundar a física social para terminar o sistema das ciências de observação" (COMTE, 1983, p. 09). Segundo ele, a física social teria a importante função de completar o ciclo das ciências naturais (aquela iniciada por Copérnico, Galileu, Descartes etc). Sendo assim, a física social, enquanto categoria distinta do pensamento cientifico, teria por função preencher as lacunas deixadas pelos conhecimentos astronômicos, físicos, químicos e fisiológicos acerca dos fenômenos sociais. Ao transpor as bases epistemológicas das ciências naturais - a saber, o racionalismo e o empirismo para o interior da Física Social, Comte estava criando seu próprio método: o método positivo. Este que, por sua vez, baseava-se em leis naturais, universais e invariáveis, sem o interesse pela explicação última da natureza (metafísica), caracterizando, assim a edificação da filosofia positiva e o apogeu da evolução do espírito humano. Neste sentido, o positivismo comteano derivou da tradição renascentista, representada principalmente por Galileu, Bancon e Descartes, ou seja, Comte transpôs os pressupostos metodológicos aplicados às ciências da natureza para o conhecimento humano (RODRIGUES, 2007). Em síntese, Comte deu inicio aos estudos sociais da ciência ao formular o marcante processo de desenvolvimento do espírito humano, reportando-se desde os pressupostos divinos e tradicionais até os postulados científicos (contidos nas ciências duras) que fundaram e consolidaram a ciência moderna.

Os fatores que apontam para a consolidação da ciência nos séculos XVIII e XIX encontramse, principalmente, no desenvolvimento do capitalismo, da indústria, da agricultura, dos transportes e, consequentemente, da tecnologia. Schwartz (1992), destacando o amplo crescimento econômico europeu, salienta que o comércio exterior da Inglaterra dobrou na primeira metade do século XVIII e os produtos ingleses para exportação aumentaram quatro vezes entre 1700 e 1790. Na França, o comércio exterior obteve um aumento três vezes maior entre 1716 e 1755 e, posteriormente, entre 1755 e 1789, voltou a duplicar. Além disso, a riqueza nacional da França teve um aumento muito significativo, passando de 731 milhões de francos, em 1715, para 2 bilhões de francos em 1788. Deste modo, o surgimento da burguesia, o modelo econômico colonial europeu e a primeira Revolução Industrial, produto do "novo conhecimento": a ciência, marcaram a solidificação da mesma como um principio de desenvolvimento da sociedade não apenas europeia. A ciência associada à ascensão do modo de produção capitalista passa a ter uma dimensão aplicada: a tecnologia; neste sentido, Schwartz (1992) afirma que o vapor foi a primeira das duas grandes inovações tecnológicas, seguido pela invenção da eletricidade. Ainda para o autor, a segunda metade da Revolução Industrial fora marcada, especialmente, pelo surgimento da eletrônica. O 


\section{A Ciência Moderna e a sua consolidação: é possível falar em crise social e epistemológica?}

telégrafo, em 1837; a galvanoplastia ${ }^{10}$, em 1840; o cabo transatlântico, em 1857; a luz elétrica, em 1840; o dínamo ${ }^{11}$, em 1867; a lâmpada incandescente, em 1878; as usinas elétricas, em 1880 e a transmissão radiofônica, em 1894 ilustram o período de abundância dos produtos da ciência.

Foi, entretanto, a teoria da relatividade, do físico alemão Albert Einstein, em 1905, que culminou, consolidou ${ }^{12}$ - alguns anos mais tarde abriu espaço para a física quântica - as descobertas, até então, realizadas pela ciência, principalmente no âmbito da física clássica. Em regras gerais, embora Einstein fora visto como físico clássico, pois não considerou o fato de que o universo expandia-se, a teoria da relatividade marcou uma transformação da ideia absoluta - a mecânica de Newton e tudo que se seguiu na física clássica até Einstein - para uma visão relacional entre tempo e espaço. Tal postulado resultou na perspectiva de que "a geometria do espaço e do tempo, que para Newton eram absolutos e eternos, torna-se dinâmica, contingente e regida por leis" (SMOLIN, 2004, p. 268). Foi a partir da teoria da relatividade que os cientistas puderam, então, calcular a idade do universo e, com isso, construir as bases históricas sobre a evolução universal. Assim, a teoria da relatividade foi fundamental para uma conclusão brilhante da física do século XIX

A surpreendente descoberta de que o espaço, antes considerado um mero pano de fundo dos fenômenos, tinha uma estrutura, cuja geometria era determinada pela distribuição da matéria e que podia variar no tempo, foi uma conquista que não pode ser atribuída somente a Einstein e sim a toda uma trajetória social e humana. [Neste sentido], a segunda lei da termodinâmica nos fez aceitar que não podemos produzir uma máquina a vapor perfeita. A teoria da relatividade especial, que nada pode ser mais veloz do que a luz. E a teoria da relatividade geral, que a geometria não é uma questão de raciocínio abstrato, e sim um propriedade mensurável do universo (SCHWARTZ, 1992, p. 103-104).

De fato, a teoria da relatividade, somada às descobertas anteriores da física e da ciência como um todo - iniciadas pelos primeiros pensadores modernos, sobretudo com o francês René Descartes e o seu método analítico -, fora o evento marcante do ápice do desenvolvimento da sociedade, da tecnologia e do conhecimento cientifico no ascender das luzes do século XX. A ciência moderna, em sua totalidade, caracterizada pela analítica cartesiana, teve um importante papel para o processo de crescimento e desenvolvimento do universo social. Neste sentido, a síntese que fizemos das principais características desse momento criativo da humanidade mostra-nos o quanto a ciência avançou, e ainda tem avançado na busca constante de novos achados sobre o mundo fenomênico.

\footnotetext{
${ }^{10}$ Processo de galvanização.

${ }^{11}$ Aparelho que converte energia mecânica em energia elétrica.

${ }^{12}$ Ao comentarem sobre o "sucesso popular" e, também, das transformações da teoria de Einstein no que concerne à comunidade cientifica e à sociedade como um todo, Collins e Pinch (2003, p. 51) salientam que "isso teve um pouco a ver com o fim da Primeira Guerra Mundial e o efeito unificador da ciência em um continente fragmentado, as dramáticas circunstâncias e a natureza evidente da 'prova' da relatividade de 1919".
} 


\subsection{A modernidade e o século XX: início de uma crise?}

$\mathrm{O}$ século XX foi, de fato, marcado por inúmeras transformações e acontecimentos no que tange ao cenário social e ao conhecimento cientifico. Dentre eles, destacam-se as descobertas da física e da ciência em geral, os avanços tecnológicos proporcionados pela segunda Revolução Industrial, com as novas fontes de energia, eletricidade e petróleo; as duas Guerras Mundiais; a Guerra Fria, com seus investimentos e descobertas no setor bélico; e, posteriormente a partir da segunda metade do século, o surgimento da Cibernética e partir de então as tecnologias informação e a chamada da Sociedade do Conhecimento, frutos da Sociedade Pós-Industrial.

Dessa forma, o pensamento moderno e o desenvolvimento da ciência clássica (linear), fundada na matriz disciplinar mantiveram-se frutíferos até meados do século XX, quando passaram a sofrer duras críticas devido ao caráter simplificador, fragmentador, analítico e linear - herança do método dedutivo de Descartes e do método indutivo de Bacon - o qual via o mundo como uma máquina, como um relógio que funcionava perfeitamente através da sincronia entre as partes que o constituía. A ciência moderna, no século XX, sobretudo a partir de sua segunda metade, apresenta sinais de esgotamento, especialmente no que se refere a sua fundamentação epistemológica e metodológica. Neste momento, podemos considerar que a ciência moderna, começa, de fato, a mostrar importantes sinais de "tensão" paradigmática, nos termos de Kuhn (1996). Isto ocorre, em verdade, como veremos, posteriormente à crise do positivismo lógico, com o surgimento da filosofia da linguagem ${ }^{13}$ hermenêutica e com as abordagens epistemológicas de orientação histórica (RODRIGUES, 2007).

O positivismo lógico, como movimento cientifico-intelectual, nasceu em Viena e formou-se por meio da reunião de filósofos, matemáticos, historiadores, sociólogos e físicos que, por seu turno, constituíram o Círculo de Viena. Foi liderado por Moritz Schlick e consolidou-se como escola no ano de 1929 (RODRIGUES, 2007). A escola filosófica do positivismo lógico ${ }^{14}$, que não

\footnotetext{
13 “Ainda que possa ser encontrada em outras áreas, a expressão "virada lingüística” ou "giro lingüístico" (linguistic turn) é típica do campo filosófico. Designa o predomínio da linguagem sobre o pensamento como um dos objetos da investigação filosófica. De acordo com o filósofo estadunidense Donald Davidson (1917-2003), é uma expressão que nomeia um novo paradigma quanto ao modo de se fazer filosofia e que veio para ficar" (Paulo Ghiraldelli Jr. 2008) acessado na Internet em 23/10/13: Virada Lingüística $\quad-\quad$ Um verbete: http://ghiraldelli.files.wordpress.com/2008/07/virada.pdf.

${ }^{14}$ Outros nomes também foram dados ao positivismo lógico, tais como: empirismo lógico; empirismo cientifico e neopositivismo lógico (TAMAYO, 2003).
} 


\section{A Ciência Moderna e a sua consolidação: é possível falar em crise social e epistemológica?}

passara de 25 membros $^{15}$, nomeada assim por Blumberg e Feigl, assentou suas bases no empirismo inglês, sobretudo nas concepções ametafisicas e positivistas de Ernst Mach (TAMAYO, 2003). Segundo Tamayo (2003), no que tange as raízes do também chamado neopositivismo, as influências são diversas e inúmeras e de diferentes matrizes de pensamento, a saber, Epicuro, Hume, Leibniz, Poincaré, Feuerbach, Marx, Russel, Mill, Einstein, além de Wittgenstein. Esse último, muito presente nos postulados do positivismo lógico, mesmo não tendo vínculo com o Círculo.

Com efeito, precisamos considerar, neste cenário, a filosofia de orientação analítica para compreender as bases epistemológicas e metodológicas nas quais sustentava-se o positivismo lógico. A filosofia da linguagem analítica fora fundada por J. L Austin e modificada por J.R Searle. De acordo com Zilles (2007), ela explorava de forma sistemática as regras, as estruturas e as regularidades que estavam alicerçadas no caráter intencional do agir lingüístico. A lingüística analítica é, de modo geral, a teoria que aborda os atos de fala e que postula a ideia de que "só tem sentido as proposições que levam para enunciados de observação" (ZILLES, 2007, p. 124). Tais características tiveram grandes influências do assim chamado, "Primeiro Wittgenstein", com a sua obra Tranctus Logico-philosophicus, publicada em 1921. Em outros termos, conforme aponta Rodrigues (2007), o positivismo lógico caracterizou-se pelo principio da verificação, pelo abandono à metafísica - o que lhe aproxima do método das ciências naturais -, pelo reducionismo filosófico e pela ênfase que fora dada à estrutura da linguagem.

Entretanto, no inicio da década de 1930, o neopositivismo apresentou sinais de esgotamento devido à crise de hegemonia do método dedutivo-indutivo que permeara intensamente a ciência, desde a sua gênese até meados do século XX. Em outros termos, a exaustão dos postulados modernos, que balizaram o neopositivismo, fora relacionada, especialmente, à crise das explicações baseadas em um único sistema filosófico. Esses que, por sua vez, tinham como objetivo dar conta de todas as dimensões do saber humano (STEIN, 2001) - a saber, os metarrelatos (verdades universais), ou seja, todas as grandes filosofias de pensadores como Descartes, Hegel, Leibniz e outros. Conforme sustenta Regner (2007), em uma mesma linha de reflexão, a unidade da ciência, procedente da ideia de que os fatos são dados da observação e que são objetos a serem descobertos a partir de leis invariáveis, apresentou certo nível de dificuldade. Neste sentido, "as tentativas de estabelecer padrões e critérios únicos de cientificidade acabaram levando a uma 'implosão' da visão [positivista] orientadora [da ciência]" (REGNER, 2007, p. 110).

\footnotetext{
${ }^{15}$ Dentre os principais membros do Circulo de Viena, temos Gustav Bergmann, Rudolf Carnap, Herbert Feigl, Philipp Frank, Kurt Godel, Hans Hahn, Viktor Krafat, Karl Menger, Marcel Natkin, Otto Neurath, Olga Hahn-Neurath, Theodor Radakovic, Moritz Schlick e Friedrich Waismann (TAMAYO, 2003).
} 
NORUS - v4, n.5, jan - jul 2016.

Ernildo Stein (2001), em sua obra, "Epistemologia e Crítica da Modernidade”, argumenta, deste modo, que:

O fim da modernidade é o momento em que não foi mais possível sustentarmos que é possível, através de um único sistema filosófico, dar explicações que tenham eficácia em todos os domínios do saber humano: em nível cognitivo, em nível de conhecimento, em nível prático, em nível moral e também em nível subjetivo, em nível artístico. No momento em que perdemos esta unidade de sistema ou a possibilidade de haver um sistema filosófico que explique as diversas regiões fundamentais do saber e do convívio humano, neste momento, chegamos ao fim da modernidade (...)A ideia de que a fé na ciência, no produto da ciência, na tecnologia, enquanto era a fé na possibilidade de uma verdade a ser buscada, também se esvaziou. De tal maneira que não buscamos mais nas ciências a verdade. A ciência procura certezas que lhe permitem eficácia em certos níveis. No momento em que desaparece a confiança e a fé nas ciências (...) temos outro sinal claro do fim da modernidade. (STEIN, 2001, p. 22)

O termo "fim" utilizado por Stein parece representar uma metáfora da relação moderno/pósmoderno. Percebemos que a noção de fim, por ele utilizada significa, antes, uma ideia de crise ${ }^{16}$ dos pressupostos modernos, tanto da filosofia como da ciência. Assim, o fim da modernidade não significa que a ciência moderna, para além de um momento histórico, esgotou-se, mas sim, que esta encontra-se num momento crítico, de exaustão. Em outras palavras, conforme bem enfatiza Rodrigues (2003, p. 77):

O emprego do termo [crise] tem sido associado a uma conotação de 'negatividade'; ou seja, impossibilidade, inexistência ou niilismo. Dessa forma, crise da modernidade significa: não (mais) modernidade; crise da ciência, não (mais) ciência; crise das instituições, não (mais) instituições (...). Propomos que o termo 'crise' seja explorado a partir de uma significação mais ampla, que contemple uma conotação de 'positividade'; uma vez que o termo em si não significa, obrigatoriamente, uma 'negatividade', isto é, implica antes, alteração, mudança, transformação, metamorfose (além da forma). Neste sentido, a crise pode ser vista como uma crise por crescimento, abundância ou excesso característico da própria modernidade (...).

Com efeito, a ciência moderna, após os séculos de descobertas e de consolidação, vê-se agora num cenário em que seus pressupostos, que tinham na crença cientifica a prenuncia do progresso, tornarem-se passíveis de questionamentos. Se o projeto da modernidade, em regras gerais, baseado, sobretudo na analítica cartesiana, anunciava a liberdade, a fraternidade e a igualdade entre os indivíduos, o que ocorreu para que esse projeto não tenha, de fato, em sua totalidade, se concretizado? Porque os metarrelatos ou as verdades absolutas e universais passaram a ser fortemente contestados? O que houve com o método receivid view (concepção herdada ${ }^{17}$ ) que

\footnotetext{
${ }^{16}$ Focamos, neste trabalho, na crise da ciência. Contudo, sabemos que a crise da modernidade também estende-se ao campo da cultura, da arte, da política, englobando, neste sentido, toda uma concepção de mundo.

17 “O termo surgiu logo após o contexto da publicação da "ERC”. Putnam, um dos principais críticos do positivismo denominou essa corrente de pensamento analítico, que havia se ampliado e se enriquecido sob a interação com diversas linhas de pensamento. O termo "Concepção Herdada" - em inglês, "Received View" - passou a ser utilizado para caracterizar uma perspectiva sobre a ciência em que ele se apresentava como se fosse imune ao contexto social; compreendida como autosuficiente, auto-explicativa, auto-referenciada; um sistema praticamente fechado, desvinculado
} 


\section{A Ciência Moderna e a sua consolidação: é possível falar em crise social e epistemológica?}

já não consegue mais dar conta de desvendar os objetos do mundo através de seu processo analítico?

Dentro deste contexto de crise, da ciência moderna, e em busca de algumas respostas às perguntas anteriores, precisamos considerar a filosofia da linguagem hermenêutica, situada no "Segundo Wittgenstein", no livro "Investigações filosóficas", de 1953, publicado post-mortem. A filosofia da linguagem de orientação hermenêutica encontra-se atrelada a Martin Heidegger e a sua perspectiva interpretativista da realidade. Em síntese, Heidegger "tenta esclarecer a linguagem a partir do ser, como 'casa do Ser"” (ZILLES, 2007, p. 125), enfatizando, deste modo, os postulados hermenêuticos da interpretação e compreensão para dar sentido à linguagem.

É importante destacar que a neutralidade, a verdade absoluta, baseada seja na razão, seja na experimentação; o universo social como um universo físico, as leis universais, entre outras características da ciência moderna, tem apresentado sinais de exaustão frente à descrença nos postulados do método analítico para a explicação dos fenômenos. Estes sinais tem se apresentado devido a uma série de fatores sociais, teóricos, epistemológicos, metodológicos e filosóficos. Dentre eles poderíamos trazer as reflexões da dimensão hermenêutica que os críticos da modernidade têm utilizado para apontar as lacunas e fragilidades da racionalidade instrumental presente no método dedutivo-indutivo. De acordo com os argumentos de Stein (1996), as estruturas lógicas não conseguem dar conta por inteiro de conhecer as coisas e os objetos. A partir disso, a hermenêutica ou a compreensão ou a interpretação passam a ser centrais na análise do mundo através dos significados. Significados esses, segundo o autor, contextualizados historicamente e culturalmente. É preciso, pois, ao lado da forma lógica colocar a interpretação via contexto (STEIN, 1996).

Diante do exposto, a relação entre sujeito e objeto também transforma-se. Se o método indutivo-dedutivo dos pensadores modernos postulava a ideia de um amplo afastamento (a questão da neutralidade axiológica) entre o sujeito que conhece e o objeto a ser conhecido, isso muda com a hermenêutica. Neste sentido, o sujeito está imerso no contexto do objeto, ou seja, conforme argumenta Stein (1996, p. 24), baseado nas teorizações de Heidegger, "a concepção do método hermenêutico justamente traz dentro de si a ideia de que no método hermenêutico a relação entre sujeito e objeto se dá numa relação de circularidade. Existe um compromisso entre sujeito e objeto no universo hermenêutico". Portanto, ao nos reportarmos à linguagem e à comunicação, podemos dizer que "existe um logos que se bifurca: o logos da compreensão da linguagem, que comunica e o logos no qual dá o sentido que sustenta a linguagem" (STEIN, 1996, p. 27). Segundo o autor, o

do meio (social, cultural, político e econômico) onde realizava a sua atividade de "gerar" conhecimento" (RODRIGUES, 2005, p. 114; nota 53). 
NORUS - v4, n.5, jan - jul 2016.

primeiro será denominado por Heidegger de logos apofântico e o segundo como logos hermenêutico. Assim,

não existe simplesmente uma verdade. Podemos falar em duas verdades. Existe verdade como propriedade das proposições pelas quais nos comunicamos e existe a verdade como fundamento da verdade das proposições. Esta segunda não precisamos chamar de verdade, podemos dar-lhe, por exemplo, o nome de sentido. O sentido sustenta a verdade das proposições (STEIN, 1991, p. 27)

Percebemos, a partir de tais argumentos, que a hermenêutica abre espaço para as possibilidades de interpretação do mundo para além das explicações baseadas em sistemas únicos, oriundos da lógica clássica e formal aristotélica e retomada pelos arautos da ciência moderna. Isto não implica que a lógica formal seja descartada, mas que a coloca como insuficiente para dar sentido aos objetos do mundo, evidenciando, dessa forma, o caráter de compreensão histórico e cultural da hermenêutica que, de certo modo, vai de encontro aos pressupostos de verdades únicas e absolutas sobre o mundo fenomênico. Assim, o método cientifico único dos cânones modernos, com a perspectiva da aplicabilidade, da busca por leis universais, formuladas em termos da matemática, dos fatos que são dados pela observação de maneira interpessoal e da validade supracontextual, inicia um processo de esgotamento (REGNER, 2007). Regner (2007, p. 111), resumindo esta ideia, ainda acrescenta que:

\begin{abstract}
A direção da atenção à contextualidade teórica inclina-se a uma visão de ciência que privilegia uma visão pluralista, não só de teorias, mas de suas metodologias. Qualquer que seja o sentido que se possa atribuir a 'paradigma', como diretrizes orientadoras quanto o que cabe ser visto, ao modo de vê-lo e de analisá-lo, o Positivismo Lógico parece ter proporcionado um paradigma para o que seja Ciência. Assim, a insatisfação para com a visão positivista e a crescente ênfase da contextualidade colocam tal "paradigma" em crise e levam a uma nova filosofia da ciência, historicamente inclinada.
\end{abstract}

Deste modo, a partir da segunda metade do século XX, emerge um intenso debate filosófico, epistemológico, histórico e sociológico acerca das possibilidades, potencialidades e limites da ciência. Destacam-se, então, neste cenário Georges Canguilhem, Thomas Kuhn, Imre Lakatos, Gaston Bachelard, Paul Feyerabend e Michel Foucault ${ }^{18}$. Em resumo, o debate que surge desses proeminentes epistemólogos diz respeito às discussões que, por se turno, abordaram a possibilidade de a ciência falar verdadeiramente acerca do mundo, independentemente do tempo e do espaço.

\footnotetext{
${ }^{18}$ Posteriormente, mais especificamente a partir da década de 70, o debate se tornou mais acirrado nos âmbitos da Sociologia e da Antropologia, os agora chamados Science Studies, com diferentes abordagens (observacionais, construtivistas, linguísticas etc.), desenvolvidas por autores tais como: David Bloor (1976; 1984; 2000); Barry Barnes (1977; 1989); Peter Slezak (1989); e Sergio Simon (1993); Karin Knorr-Cetina (1983; 1991); Bruno Latour e Steve Woolgar (1986; 2005) Bruno Latour (2000; 2011); Harry Collins e Trevor Pinch (2010) e têm se estendido até os dias de hoje.
} 


\section{A Ciência Moderna e a sua consolidação: é possível falar em crise social e epistemológica?}

Ademais, esses pensadores questionaram o monismo metodológico presente no método cartesiano e a divisão social do trabalho, principalmente no que tange à ciência internalista e externalista, isto é, a lógica da descoberta e a sua possibilidade de justificação. Esses debates se fizeram mais intensos, sobretudo após o paradigmático ensaio elaborado por Thomas Kunh, a saber, "A estrutura das revoluções cientificas”, publicado originalmente em 1962. É neste sentido que Rodrigues (2005, p. 114) argumenta que:

Embora os estudos filosóficos da ciência já tivvessem levantado importantes questões quanto aos limites do método indutivista-dedutivista, primeiramente, com os argumentos trazidos por Duhem (1914) que ficaram conhecidos como a "Tese de Duhem-Quine"; e, mais tarde, com a chamada "Tese-da-Carga-Teórica", somente após a obra de Kuhn, ("ERC"), os cientistas sociais da ciência, em particular os sociólogos, aventuraram-se a adotar argumentos de natureza lógico-filosóficas com o objetivo de enfraquecer a hegemonia do indutivismo-dedutivismo como núcleo da chamada Concepção Herdada.

Em relação ao debate central desses sociólogos, historiadores e filósofos da ciência sobre as mudanças de visão do fazer cientifico, Regner (2007) argumenta que a compreensão acerca da ciência abandonou a busca de fundamentos e de conjuntos de regras fixas e universais. Deste modo, para a ciência, à luz das observações da vida cientifica, "os sólidos fatos tornaram-se maleáveis, com divergências entre pessoas observando os mesmos fatos (REGNER, 2007. p. 111). Esses fatos, segundo a autora, quando refere-se à essência da crítica dos referidos epistemólogos, nunca são apenas fatos, mas sim fatos produzidos dependentemente da própria teoria. Neste sentido, a necessidade da diversidade de teorias e metodologias, contrapondo a perspectiva do monismo metodológico ou a unidade do método cientifico, ${ }^{19}$ é a chave para entendermos a crise da ciência moderna, frente à pluralidade e frente à dinamicidade do mundo contemporâneo (REGNER, 2007)

Precisamos atentar, então, para o fato de que a modernidade - neste sentido nos referirmos centralmente a ciência como um das realizações do conhecimento humano mais importantes deste período - não se exauriu por completa. Seja ela uma modernidade radicalizada, como queira Giddens, ou um projeto inacabado, como definiu Habermas. O importante é salientar que a crise é o próprio debate sobre a crise. Conforme Regner (2007) os estudos sociais da ciência - com o objetivo de compreender a ciência a partir de seu enfoque contextual principalmente através dos influentes epistemológos anteriormente mencionados - ao colocar em questionamento o monismo metodológico dedutivo-indutivo da ciência moderna, principalmente do positivismo lógico, sinalizaram e consolidaram, de vez, a intensa crise dos postulados da ciência, baseada, sobretudo, na analítica cartesiana.

Assim, conforme ilustra Stein (2001, p. 15), "este ponto da modernidade [tomando] consciência de si mesma é a modernidade tornando-se crítica e, de certo modo, trazendo em si

\footnotetext{
${ }^{19}$ Ver Von Wrigth, p.21 apud Bombassaro, 1992, p. 30.
} 
NORUS - v4, n.5, jan - jul 2016.

mesma o conceito de crítica da modernidade”. Ora, se a crise é uma realidade para o debate que se dá no interior dos estudos sociais da ciência, mas faz-se ausente para os representantes modernos, pois existem dúvidas em relação a uma total ruptura como ocorrera, por exemplo, entre o pensamento moderno e o pensamento medieval, então ela pode bem caracterizar-se como uma “presença ausente", ou seja, ela está presente no debate epistemológico acerca dos limites da ciência moderna, porém faz-se ausente para os representantes modernos.

O que ocorre, de fato, com a ciência, na nossa opinião, é uma crise de diversificação. Diversificação da ciência e também da sociedade - que ao transformar-se, também modifica a ciência -, pois ambas estão inextricavelmente relacionadas. Deste modo, se a complexidade do tecido social tem apresentado-se cada vez maior, a ciência não tem ficado estática perante a essa dinâmica, tornando-se, também, mais complexa. Essa característica reivindica, assim, uma nova postura cientifica, que vá para além dos sistemas únicos e que transponha, neste sentido, os limites do conhecimento herdados da analítica cartesiana, lançando, a partir disso, olhares para o universo, seja ele natural ou social, de maneira plural, ou seja, complexa.

\section{Referências Bibliográficas}

ANDERY, Maria Amália et al. Para compreender a Ciência: uma perspectiva histórica. São Paulo: EDUC, 1988.

BAUMER, Franklin L. O pensamento europeu moderno: volume I Séculos XVII e XVIII. Rio de Janeiro: edições 70, 1990.

BOMBASSARO, Luiz Carlos. As fronteiras da epistemologia: uma introdução ao problema da racionalidade e da historicidade do conhecimento. Petrópolis: Vozes, 1992.

CAPRA, Fritjoj. O Ponto de Mutação. São Paulo: Círculo do livro, 1972.

COLLINS, Harry; PINCH, Trevor. O golem: o que você deveria saber sobre ciência. São Paulo: Editora UNESP, 2003.

COMTE, Auguste. Curso de Filosofia Positiva: Discurso sobre o espírito positivo. In: Os

Pensadores. São Paulo: Abril Cultural, 1983.

DESCARTES, René. Discurso do Método. In: Os Pensadores. São Paulo: Abril Cultural, 1983.

FOUCAULT, Michel. As palavras e as coisas: uma arqueologia das ciências humanas. São Paulo: Martins Fontes, 2000.

GRANGER, Gilles-Gaston. Introdução. In: DESCARTES, René. Discurso do Método. In: Os Pensadores. São Paulo: Abril Cultural, 1983, p. 05-24. 
A Ciência Moderna e a sua consolidação: é possível falar em crise social e epistemológica?

KOYRÉ, Alexandre. Estudos de História do Pensamento Cientifico. Brasília: Universidade de Brasília, 1982.

As origens da Ciência Moderna: uma nova interpretação. In: KOYRÉ, Alexandre.

Estudos de História do Pensamento Cientifico. Rio de Janeiro: Forense, 2011, p. 55-81.

Do Mundo Fechado ao Universo Infinito. Rio de Janeiro: Forense Universitária, 2011.

KUHN, Thomas. A Estrutura das Revoluções Científicas. São Paulo: Perspectiva, 1996.

LOSEE, John. O Homem e a Ciência: introdução histórica à Filosofia da Ciência. São Paulo:

Ed. Universidade de São Paulo, 1979.

MOREIRA, Marco Antônio; MASSONI, Neusa Teresinha. Epistemologias do século XX:

Popper, Kuhn, Lakatos, Laudan, Bachelard, Toulmin, Feyerabend, Maturana, Bohm, Bunge, Prigogine, Mayr. São Paulo: E.P.U, 2011.

MOTTA, Manoel Barros Da. Apresentação. In: KOYRÉ, Alexandre. Do Mundo Fechado ao Universo Infinito. Rio de Janeiro: Forense Universitária, 2011, p. V-XIII.

M581. 1001 Invenções que mudaram o mundo. Rio de Janeiro: Sextante, 2010.

NORBERT, Elias. A sociedade dos indivíduos. Rio de Janeiro: Zahar, 1994.

Paulo Ghiraldelli Jr. 2008: acessado na Internet em 23/10/13: Virada Lingüística - Um verbete: http://ghiraldelli.files.wordpress.com/2008/07/virada.pdf .

REGNER, Anna Carolina K.P. Filosofia da ciência hoje. In: BIRCK, Odélio Bruno, RODRIGUES, Leo Peixoto, PIVATTO, Pergentino S. (Orgs). Filosofia na atualidade. Porto Alegre: EDIPUCRS, 2007, p. 109-118.

RODRIGUES, Leo Peixoto. A (des) estruturação das estruturas e a (re)estruturação dos sistemas: uma revisão epistemológica crítica. In: RODRIGUES, Léo Peixoto; MENDONÇA, Daniel de (Orgs). Ernesto Laclau e NiklasLuhmann: pós fundacionalismo, abordagem sistêmica e as organizações sociais. Porto Alegre: EDIPUCRS, 2006, p. 35-67

. A Filosofia e o desafio contemporâneo: trata-se de uma perspectiva meramente epistemológica? In: BIRCK, Odélio Bruno, RODRIGUES, Leo Peixoto, PIVATTO, Pergentino S. (Orgs). Filosofia na atualidade. Porto Alegre: EDIPUCRS, 2007, p. 83-108.

. A Universidade como organização moderna: os desafios contemporâneos não são apenas epistemológicos. In: SILVEIRA, Flavio Eduardo (org.). Organizações e Sociedade: Identidade, Poder, Saber e Comunicação na Contemporaneidade. Porto Alegre: EDIPUCRS, 2003.

. RODRIGUES, Léo Peixoto. Introdução à Sociologia do Conhecimento da Ciência e do Conhecimento Científico. Passo Fundo: Editora da UPF, 2005.

ROLAND, Omnes. Filosofia da Ciência contemporânea. São Paulo: UNESP, 1996.

SCHWARTZ, Joseph. O momento criativo: mito e alienação na Ciência Moderna. São Paulo: Círculo do livro, 1992. 
NORUS - v4, n.5, jan - jul 2016.

SHORTO, Russel. Os ossos de Descartes: a história do esqueleto por trás do conflito entre fé e razão. Rio de Janeiro: Objetiva, 2013.

SANTOS, Boaventura de Sousa. Introdução a uma ciência pós-moderna. Rio de Janeiro: Graal, 1989.

SMOLIN, Lee. A vida do cosmos. São Leopoldo: Editora Unisinos, 2004.

STEIN, Ernildo. Aproximações sobre Hermenêutica. Porto Alegre: EDIPUCRS, 1996.

. Epistemologia e critica da modernidade. Ijuí: UNIJUÍ, 2001.

TAMAYO, Raul Pérez. Existe el método cientifico? México: FCE, SEP, CONACyT, ENC, 2003.

ZILLES, Urbano. Correntes e problemas na Filosofia contemporânea da linguagem. In: BIRCK, Odélio Bruno, RODRIGUES, Leo Peixoto, PIVATTO, Pergentino S. (Orgs). Filosofia na atualidade. Porto Alegre: EDIPUCRS, 2007, p. 109-118. 